\title{
Películas-voz: estéticas de no ficción decolonial en Barcelona
}

\section{Voice-films: Decolonial non ficiton aesthetics in Barcelona}

\author{
Joan Miquel Gual \\ Universitat Oberta de Catalunya
}

Fecha de recepción: 29 de mayo de 2018

Fecha de aceptación: 15 de mayo de 2019

\author{
Anuario del Departamento de Historia y Teoría del Arte \\ vol. 31, 2019, pp. 75-92 \\ ISSN: 1130-5517, eISSN: 2530-3562 \\ https://doi.org/10.15366/anuario2019.31.004
}

\begin{abstract}
RESUMEN
La investigación decolonial estudia la configuración del mundo después del final de las colonias. Las diásporas globales, las relaciones norte-sur, la pervivencia de rastros coloniales en las antiguas metrópolis y colonias, la situación de dominio neocolonial impuesta por algunas multinacionales o las luchas de liberación contra este marco político son algunos de los temas recurrentes. De manera más importante para el texto que se presenta a continuación, esta rama de estudios también abarca la representación de los conflictos urbanos vinculados al sistema de fronteras. En el caso de Barcelona han aparecido un número significativo de títulos de no ficción caracterizados por algún tipo de alianza entre personas y colectivos locales y migrantes. Tales alianzas erigen una perspectiva crítica encarnada y situada que contribuye, desde el campo de la producción audiovisual, a la protesta en contra del racismo y el régimen de fronteras dentro de la propia ciudad. La función decolonial perseguida por los títulos de no ficción que se analizarán es la circulación de materiales, algunas veces de urgencia, que sirven para contraatacar los discursos hegemónicos criminalizadores y las múltiples invisibilizaciones de colectivos humanos racializados, fruto de fronteras que son herencia de un pasado colonial que en gran parte se mantiene vigente.
\end{abstract}

\section{PALABRAS CLAVE}

Decolonialidad. Luchas urbanas. Cine de no ficción. Iconografía. Movimientos sociales. Migración. Sin papeles. Ciudadanía.

\begin{abstract}
The decolonial investigation studies the configuration of the world after the end of the colonies. The global diasporas, the north-south relations, the survival of colonial traces in the old metropolis and colonies, the situation of neocolonial domination imposed by some multinationals or the liberation struggles against this political framework are some of the recurring themes. More importantly for the text presented below, this branch of studies also covers the representation of urban conflicts linked to the border system. In the case of Barcelona, a significant number of non-fiction titles have appeared, characterized by some kind of alliance between local and migrant groups. Such alliances offer a critical perspective that contributes, from the field of audiovisual iconography, to increase the protest against racism and borders within the city itself. The decolonial function pursued by the non-fiction titles that will be analyzed here is the circulation of ideas, sometimes useful to different emergences, which serve to counteract the hegemonic discourses of criminalization and the multiple invisibilisations of racialized human collectives, resulting from frontiers that are the heritage of a colonial past which to a large extent it remains alive.
\end{abstract}

\section{KEY WORDS}

Decoloniality. Urban struggles. Nonfiction cinema. Iconography. Social movement. Migration. Sans papier. Citizenship. 


\section{Estéticas decoloniales de no ficción}

A finales de 2010, tuvo lugar en tres espacios diferentes de la ciudad de Bogotá la muestra Estéticas decoloniales. Con la misma, los curadores Walter Mignolo y Pedro Pablo Gómez llevaron a cabo una indagación sobre el carácter decolonial de unas propuestas artísticas movilizadas por una pregunta "que indaga por la posibilidad de construir, no tanto modernidades alternativas, sino alternativas a la modernidad [...] recogiendo los legados históricos de resistencia y lucha de individuos y comunidades"1. Alternativas a la modernidad que "puedan convertirse en otra opción civilizadora que decolonice cada una de las dimensiones de la modernidad en las que la acción de la colonialidad se instala y se naturaliza"2.

El punto de partida del proyecto resulta manifiestamente claro: la ocultación implícita de la herida colonial en el arte y la estética occidentales, una herida que "influencia los sentidos, las emociones y el intelecto"'. De hecho, la muestra perseguía el objetivo doble de avanzar en la conceptualización de la decolonización de la estética y la liberación de la aisthesis o el sentir de los colonizados. Para ello ofreció diferentes operaciones de lo sensible o creaciones estéticas llevadas a cabo por artistas procedentes de diferentes países que hoy sufren formas de dominación debidas a la situación de colonialidad.

La herida colonial fue conceptualizada de manera muy influyente en los años sesenta por el psiquiatra y luchador anticolonial Frantz Fanon. Los condenados de la tierra es una obra de referencia que rechazó la idoneidad de las ideas marxistas para explicar de manera efectiva la herida psíquica que implica todo proceso de emancipación colonial. Este pensador fue, sin lugar a dudas, un punto de anclaje para el movimiento del Tercer Cine, cuya meta estético-política primordial fue "la gran posibilidad de construir desde cada pueblo una personalidad liberada: la descolonización de la cultura"4. Este objetivo resuena de manera clara en el ideario y las propuestas estéticas decoloniales actuales, si bien de manera distinta, tal como veremos a continuación.

A diferencia de los filmes predecesores del Tercer Cine, las películas de no fícción que aquí tomaremos en consideración no se inscriben en un imaginario cultural de tipo nacional-popular, ni pueden ser consideradas como una escuela o un movimiento con rasgos definitorios. Su apuesta política-estética puede ser pensada más bien como acciones de sensibilización radical en el marco de la diáspora y los retos actuales del movimiento antirracista, el cual señala cada vez con mayor intensidad el vínculo entre la condición migrante y el expolio y la dominación que continúa vigente hoy, después del fin oficial de las colonias.

Dicho esto, ¿en qué consiste el corpus de no ficción elegido? ¿Por qué puede ser enmarcado dentro de las estéticas decoloniales? ¿Cómo puede contribuir a la liberación del sentir fuertemente condicionado por la herida? Para tratar de responder a estas cuestiones, cuyo alcance va mucho más allá de la finalidad de este breve escrito académico, se señalarán de manera preliminar dos aspectos primordiales, que más tarde se desarrollarán. En primer lugar, aquí serán tenidas en consideración una serie de piezas directamente vinculadas a organizaciones, movimientos y personas que trabajan activamente para desprenderse de la colonialidad existente en Barcelona, independientemente de si se reconocen o no explícitamente dentro del giro decolonial. En segundo lugar, otra aportación importante del texto será intentar establecer un diálogo entre el corpus decolonial elegido con imágenes provenientes del siglo XX, la cuales muestran y reflexionan sobre la condición migrante cuando estaba encarnada por personas pertenecientes al mismo Estado español, quienes, no por ello estaban a salvo de ser expulsadas de la urbe, vilipendiadas por su origen y criminalizadas en su intento de buscar una vida mejor a través del gesto migratorio. De esta manera se per-

\footnotetext{
1 Pablo Gómez, Walter Mignolo, Estéticas decoloniales, Facultad de Bellas Artes de la Universidad Distrital Francisco José de Caldas, Bogotá, 2012, p. 16.

2 Ibidem, p. 16.

3 Ibidem, p. 9.

4 Fernando Solanas, Octavio Gettino, "Hacia un tercer cine", en Octavio Gettino, A diez años de "Hacia un Tercer Cine", México, Filmoteca de la UNAM, 1982, pp. 37-54.
} 
sigue la finalidad de pensar, a partir del rico archivo local de no ficción, puntos de confluencia entre presente y pasado, así como visibilizar un objetivo político que reside en todas las películas seleccionadas, orientado a la curación de la herida: la construcción y difusión de formas de empatía radical, base sine qua non de cualquier transformación política.

Para llevar a cabo todo lo descrito hasta aquí, en primer lugar, es necesario hacer una aclaración teórica: la colonialidad no es sinónimo de colonialismo. Para apuntalar esta afirmación, utilizaremos las palabras de uno de los principales filósofos decoloniales del presente:

Colonialismo denota una relación política y económica, en la cual la soberanía de un pueblo reside en el poder de otro pueblo o nación, lo que constituye a tal nación en un imperio. Distinto de esta idea, la colonialidad se refiere a un patrón de poder que emergió como resultado del colonialismo moderno, pero que en vez de estar limitado a una relación formal de poder entre dos pueblos o naciones, más bien se refiere a la forma como el trabajo, el conocimiento, la autoridad y las relaciones intersubjetivas se articulan entre sí, a través del mercado capitalista mundial y de la idea de raza. Así, pues, aunque el colonialismo precede a la colonialidad, la colonialidad sobrevive al colonialismo 5 .

El pensamiento decolonial, cuyo punto de partida originario tuvo lugar en el Tercer Mundo, más específicamente la Conferencia de Bandung (1955), se reivindica como un giro epistémico conectado con la experiencia de frontera y la conciencia inmigrante actual:

Dado que el punto de origen de la decolonialidad fue el Tercer Mundo con su diversidad de historias y tiempos locales, y siendo diferentes países imperiales de Occidente los que interfirieron por vez primera en esas historias locales [...] el pensamiento fronterizo es la singularidad epistémica de cualquier proyecto decolonial. ¿Por qué? Porque la epistemología fronteriza es la epistemología del anthropos que no quiere someterse a la humanitas, aunque al mismo tiempo no puede evitarla. La decolonialidad y el pensamiento/sensibilidad/hacer fronterizos están por consiguiente estrictamente interconectados, dado que la decolonialidad no puede ser ni cartesiana ni marxiana. En otras palabras, el origen tercermundista de la decolonialidad se conecta con la "conciencia inmigrante" de hoy en Europa occidental y Estados Unidos. La conciencia inmigrante se localiza en las rutas de dispersión del pensamiento decolonial y fronterizo ${ }^{6}$.

Dicho esto, el repertorio audiovisual sobre migraciones que se abordará muestra diferentes dimensiones de la experiencia de frontera, específicamente de frontera interna. Critica el funcionamiento de dispositivos racistas orientados a identificar, detener y expulsar personas a causa de sus rasgos físicos y/o culturales ${ }^{7}$, desde una óptica múltiple que señala la pervivencia de la colonialidad del poder, el ser y el saber en el presente . $^{8}$

CC13 (Daniela Ortiz, Xosé Quiroga, 2013) enseña rastros del pasado colonial homenajeados a través de monumentos en la trama urbana de Barcelona. Su posicionamiento político tiene que ver principalmente

\footnotetext{
5 Nelson Maldonado-Torres, "Sobre la colonialidad del ser: contribuciones al desarrollo de un concepto", en S. Castro Gómez, R. Grosfoguel (eds.), El giro decolonial. Reflexiones para una diversidad epistémica más allá del capitalismo global, Bogotá, Iesco-Pensar-Siglo del hombre editores, 2007, p. 131.

6 Walter Mignolo, Geopolítica de la sensibilidad y el conocimiento. Sobre (de)colonialidad, pensamiento fronterizo y desobediencia epistémica [en línea], http://eipcp.net/transversal/0112/mignolo/es [Consulta: 20 de mayo 2018].

7 Las obras analizadas son mayoritariamente cortometrajes que reflexionan sobre la condición de los llamados sin papeles (todas aquellas personas y colectivos sociales excluidos de las obligaciones y derechos de ciudadanía) por un lado, o bien en un matiz distinto, sobre las y los ciudadanos irregulares a quienes se les ha negado el pleno estatus de ciudadanía (es decir, aquellas personas que, pese a no tener el riesgo de ser expulsadas, son consideradas de segunda y excluidas de derechos fundamentales como el derecho a voto).

8 "Y si la colonialidad del poder se refiere a la interrelación entre las formas modernas de explotación y dominación, y la colonialidad del saber tiene que ver con el rol de la epistemología y las tareas generales de producción del conocimiento en la reproducción de regímenes de pensamiento coloniales, la colonialidad del ser se refiere entonces a la experiencia vivida de la colonización y su impacto en el lenguaje". MALDONADO-TORRES, 2007, p. 130.
} 
con la llamada colonialidad del saber existente hoy en el marco urbanístico. La pieza señala también el desconocimiento local de toda una serie de figuras históricas que pueden resultar hirientes para quienes conocen o han experimentado la hostilidad colonial en su propia piel. Por otra parte, Nosotros, los negros (María Fernanda Borregales, Adrià Rodríguez, Ana Román, Juan Manuel Ruales, Marina Siero, Sebastián Tapia, 2016) razona sobre la colonialidad del poder, sobre la interrelación de dominación y explotación en el contexto local, a partir de una de las polémicas más duras suscitadas durante el mandato de Ada Colau: los enfrentamientos entre manteros negros y policías de la Guardia Urbana que acabaron con detenciones, un encarcelamiento y heridos leves en el otoño de 2015, después de varios episodios de represión de la venta ambulante. Este episodio defraudó las expectativas que muchos votantes y colectivos desfavorecidos tenían en el nuevo gobierno local, de claro signo progresista. Por otra parte, el tratamiento en prensa del caso fue muy crítico con la gestión llevada a cabo por los responsables municipales. Dicho tratamiento resulta cercano, como se tratará de evidenciar, al concepto de pánico moral definido en Folk Devils and Moral Panics ${ }^{9}$. De manera resumida, pánico moral es la etiqueta que recibe la reacción de un grupo de personas basada en la percepción falsa o exagerada de algún comportamiento cultural o de grupo, frecuentemente un grupo minoritario o una subcultura, definidos como peligrosamente desviados. Tal reacción se produce después de que medios de comunicación amplifiquen un episodio, condición, persona o grupo de personas que han sido catalogados como una amenaza para los valores e intereses de la sociedad. En definitiva, más que de un miedo colectivo infundado, el pánico moral se plantea como un atentado al orden social en gran parte impulsado mediáticamente.

En conexión con la idea de pánico moral, cabe decir que uno de los elementos más definitorios de la experiencia de frontera es la catalogación de las y los inmigrantes como "grupos de riesgo"10, etiqueta que los convierte en proclives a una mayor exposición al control social, a la sospecha y a tratamientos mediáticos desfavorables. Sin ir más lejos, la islamofobia puede ser pensada como resultado de esta situación en el contexto posterior al 11 de septiembre de 2001. La película Rastros de Dixán (José González Morandi, Sergi Dies, 2009) deconstruyó la falsa acusación que yacía en la denuncia contra 11 vecinos del Raval, acusados de terrorismo y encarcelados durante siete años sin más pruebas que la declaración de un testimonio protegido que, años después, se reveló falsa. Más allá, cabe poner en relación el mediometraje de Dies y González Morandi con una cuestión perenne: la existencia de los otros (inmigrantes) como un potencial peligro social, algo que se ha dado a lo largo de la historia local bajo justificaciones diferentes. En este sentido, existen otras piezas audiovisuales que comparan la condición migrante extracomunitaria actual con la migración de mediados del siglo XX, proveniente principalmente de las regiones empobrecidas del sur de España. La repetición de determinados patrones de exclusión y la pervivencia de mecanismos de control y expulsión de los otros por parte de las fuerzas del orden, así como también la imposibilidad de acceder a un trabajo digno y legal, resultan los temas principales de Mapas migrantes (David Batlle, 2009).

Por otra parte, si el título del artículo reivindica la existencia de películas-voz es debido a un hilo que las unifica: la toma de palabra orientada a decolonizar el espacio público y la política occidental va de la mano de la toma de palabra en el espacio audiovisual. Para justificar teóricamente dicho concepto nos atendremos a los conceptos de voz, lealtad y salida planteados por Hirschman en Salida, voz y lealtad: respuestas al deterioro de empresas, organizaciones y estados, donde expone una teoría general sobre el comportamiento humano basado en las formas de relación en el seno de la sociedad. Para Hirschman existen tres posibles tipos de relaciones: sentirse a gusto en la relación (Lealtad), sentirse disgustado y querer cambiarla mediante la protesta (Voz), o rechazarla y eludir la relación (Salida). Esta forma de ver las relaciones en la sociedad se ha aplicado a problemas económicos, sociológicos y políticos, y puede aplicarse a todo tipo de interrelaciones sociales, como el racismo y las fronteras.

\footnotetext{
9 Stanley CoHen, Folk Devils and Moral Panics, Londres, Routledge, 2002.

10 Alessandro DE GioRgi, Tolerancia cero. Estrategias y prácticas de la sociedad del control, Barcelona, Virus, 2005.
} 
La puesta en escena de las películas-voz fue El encierro en la Iglesia del Pi (Rabia Williams, 2004), sobre uno de los primeros encierros masivos del emergente sujeto político sin papeles en Barcelona ${ }^{11}$. La última que aquí se analizará es Idrisa, crónica de una muerte cualquiera (Metromuster, 2018), sobre la complicada repatriación del cadáver de un migrante muerto en extrañas circunstancias dentro del Centro de internamiento para inmigrantes (CIE) de Zona Franca. Una repatriación excepcional que evidencia la existencia de muchas formas de morir en el anonimato, o ser asesinado, cuando se cruza una frontera; así como también la imposibilidad que tienen las familias, en muchas ocasiones, de hacer duelo por sus muertos.

\section{Los encierros y el nacimiento audiovisual del movimiento sin papeles}

Ante la pervivencia del estigma de los fugados de sus países de origen, Sandro Mezzadra articuló años atrás una honda reflexión acerca de la necesidad de erigir un nuevo derecho legitimador del gesto migratorio: el derecho de fuga. En otras palabras, podríamos definir el mismo concepto como derecho a un estatus de ciudadanía global.

LA FUGA, COMO CATEGORÍA POLÍTICA, ha sido vista siempre con desconfianza. Cercada entre el oportunismo, el miedo y la cobardía aparece peligrosamente cercana a la traición, renegada tanto por la narrativa patriótica como por la socialista. Al fugitivo "despreocupado por el mañana", como los piratas de la Isla del Tesoro de Stevenson, le repugna el sacrificio y la abnegación, la voluntad de medirse con la aspereza del presente para construir un futuro colectivo, del mismo modo le es extraño el consecuente sentido del deber y la responsabilidad. ¿Por qué entonces titular con la fuga, y más enfáticamente con el derecho de fuga, este libro? ${ }^{12}$

Mezzadra propone pensar las migraciones como un movimiento social en favor del establecimiento de una condición de ciudadanía no vinculada a la pertenencia o no a un estado-nación, en favor de la posibilidad de establecerse en un país extranjero en igualdad de libertades, obligaciones y derechos que el resto de la población. Esta reivindicación choca y contrasta con la Carta de los Derechos Humanos de las Naciones Unidas, cuyos dos puntos del artículo 13 contemplan que:

1. Toda persona tiene derecho a circular libremente y a elegir su residencia en el territorio de un Estado.

2. Toda persona tiene derecho a salir de cualquier país, incluso del propio, y a regresar a su país.

La Carta no reconoce el derecho a la inmigración individual o colectiva y deja en manos de la soberanía nacional de los estados el régimen de circulación, residencia y expulsión. Mezzadra se enfrenta directamente con esta concepción articulando un concepto de fuga que resignifica semánticamente, sin escatimar, en una primera dimensión, múltiples referencias culturales y de imaginario social sobre la importancia política de la deserción:

Se podría recordar por cierto, y no es poca cosa en estos tiempos de guerra permanente (enduring war), que al campo semántico de la fuga pertenece un concepto como el de deserción, que el cine (empezando por Senderos de Gloria de Stanley Kubrick) y la misma historiografía ("Apología del miedo" se titulaba la introducción redactada por Enzo Forcella, en el mítico año 1968, a una famosa compilación de los fallos de tribunales militares italianos contra desertores y "derrotistas" durante la primera guerra mundial) nos han enseñado a reconocerle nobleza. No por casualidad, en los Estados Unidos de los años sesenta, un extraordinario movimiento de masas orga-

11 En este marco fue demandada una regularización masiva de habitantes en situación irregular. Esta pieza, realizada desde dentro de la protesta y adoptando el punto de vista de los sin papeles, aborda una de las acciones más radicales que tuvieron lugar poco tiempo antes de la quinta y última regularización masiva que ha tenido lugar hasta el momento en la España democrática, en el año 2005 a manos del gobierno Zapatero.

12 Sandro Mezzadra, Derecho de fuga. Migraciones, ciudadanía y globalización, Madrid, Traficantes de Sueños, 2005 , p. 43. 
nizaba la deserción a la guerra de Vietnam vinculándose con otro concepto político con el cual aquel campo semántico mantiene también relaciones conspicuas: el de desobediencia civil. También, un par de décadas después, desde la República Democrática Alemana, un masivo movimiento de fuga, de exit para decirlo con Albert O. Hirschman (1970 y 1993), inauguró los sucesos que condujeron al fin del socialismo real ${ }^{13}$.

El tema de la deserción de la guerra está hoy plenamente vigente, debido a la oleada de personas sirias, muchas de ellas soldados que no quieren participar en el conflicto y anhelan encontrar refugio en Europa. Más allá de la deserción bélica en cualquiera de sus formas, una segunda dimensión del concepto mezzadriano de derecho de fuga recuerda una amplia tradición occidental que sitúa la migración a otro país no motivada únicamente por causas materiales como el sufrimiento, el hambre o la ausencia de opciones laborales, sino con la sed de crecimiento personal y de aventura que reside en el ánimo de muchas personas en todo el mundo:

Pero la fuga en la cultura de Occidente, es también viaje, descubrimiento, sed de conocer y rechazo de aquello que Majakovskji llamaba "la banalidad de lo cotidiano": desde la experiencia arquetípica de Odiseo a los jóvenes jesuitas italianos que entre el siglo XVI y XVII fueron atraídos por el "deseo de las Indias" (Roscioni 2001), desde las muchas generaciones que persiguieron on the road un sueño de libertad, hasta las aventureras vicisitudes cinematográficas de Thelma y Louise, la figura del fugitivo se ha cargado de significados totalmente distintos a los que se concentran alrededor de la figura del cobarde. Y finalmente: ¿cómo no recordar que en el origen mismo de Occidente hay un potente mito de fuga, aquel éxodo bíblico que ha representado por siglos una metáfora de los procesos de liberación y revolución (Walzer 1985), además de haber alimentado el sacro experimento (Bonazzi 1970) de la construcción de un nuevo mundo en América que debía dejar atrás la corrupción de la vieja Europa? ${ }^{14}$.

La prolífica y caudalosa reflexión sobre el derecho de fuga nació después de la emergencia en Europa de un nuevo sujeto político, a mediados de los años noventa: los y las sin papeles. La Ballade des Sans Papiers (Samir Abdallah, Rafaelle Ventura, 1997) es probablemente el primer documental sobre el tema y un documento fundamental si se quiere rastrear la genealogía de las luchas por la libertad de movimiento y permanencia que han tenido lugar en los últimos veinte años en el viejo continente. En España, no fue hasta el año 2001 cuando se puso en escena este mismo movimiento sociopolítico. Aparte de los masivos disturbios que tuvieron lugar en Ca'n Anglada (un barrio de Terrassa, Barcelona) y El Ejido (en la provincia de Almería), también se produjeron los encierros conocidos como "los encierros de la iglesia del Pi", debido a que en esta ubicación tuvo lugar el encierro más numeroso, si bien, al mismo tiempo un elevado número de migrantes se encerró en ocho iglesias distintas del área metropolitana de Barcelona. Tras una protesta de 47 días, con huelga de hambre incluida, se consiguió la regularización de más de 14.000 inmigrantes $^{15}$.

Según la socióloga mexicana Amarela Varela, la elección de la iglesia como lugar de encierro respondió a tres motivos diferentes, muy importantes todos ellos a nivel iconográfico. En primer lugar, ya se había utilizado esta táctica, con buenos resultados, por parte "de los sans papiers franceses que desde 1996 usaban los encierros, lo mismo en centros religiosos que en instituciones gestoras de la migración, para visibilizar socialmente sus demandas"16. En segundo término, los encierros también habían sido utilizados previamente por el movimiento vecinal local y obrero en los años 60 y 70, en plena dictadura de Franco y con el derecho de reunión totalmente prohibido, por lo tanto "estaba presente como mecanismo de lucha entre los españoles"17; de hecho, se hace difícil no recordar por ejemplo las imágenes de la masacre de Vitoria en 1976, la mayor matan-

\footnotetext{
13 Ibidem, p. 44.

14 Ibidem, p. 44.

15 Blanca CiA, "1.700 inmigrantes se encierran en Barcelona en demanda de 'papeles"”, El País, 6 de junio de 2004 [en línea], https://elpais.com/diario/2004/06/06/espana/1086472814_850215.html [Consulta: 20 de mayo 2018].

16 Amarela VAREla, Por el derecho a permanecer y pertenecer. Una sociología de las luchas migrantes, Madrid, Traficantes de Sueños, 2013, pp. 101.

17 Ibidem, p. 101.
} 
za de la Transición que tuvo lugar, precisamente, en una iglesia donde se celebraba una asamblea. En tercer lugar, en las iglesias se demostraba el apoyo de los curas a la causa, una fuente inestimable de legitimidad social, y se apelaba también a la condición sagrada de los templos: "hay que señalar que para una buena parte de los participantes un centro religioso representaba en su imaginario un lugar seguro y sagrado"18.

El encierro en la Iglesia del Pi relata no ese primer encierro de 2001, sino su reedición en junio de 2004 cuando 1.500 emigrantes se recluyeron en la Catedral de Barcelona y otros 200 más en la misma iglesia del Pi, después de una manifestación. Esta acción solamente duró una noche y posteriormente ambos recintos fueron desalojados por la policía. En todo caso, el documental atesora el mérito de ser el primero sobre las asambleas y movilizaciones de sin papeles. Es el primero que ataca, desde Barcelona, la contradicción existente en una Europa que, como recuerda Mezzadra, siempre ha reivindicado el viaje y la migración como forma de conocer mundos nuevos, pero que sin embargo castiga y expulsa a muchas de las personas que llegan de fuera para vivir en su seno.

Por otra parte, podemos definir el cortometraje como un documental observacional-participante, debido a que quien filma está implicada en primera persona en la acción de protesta, adoptando un punto de vista activo y nada neutro, en favor de las personas encerradas. Más allá, este trabajo sirvió también para documentar visualmente la mutación del rostro de las migraciones, un tema que ha sido tratado en otros audiovisuales posteriores, como el que se revisará el siguiente epígrafe.

\section{Invisibles de ayer e invisibles de hoy}

Las fronteras, en el siglo XX, no separaban solamente dos territorios soberanos, sino que vetaban la libre circulación de las personas de menor poder adquisitivo en el marco del Estado español mismo. Mapas migrantes está compuesto de 3 postales en movimiento que dialogan entre ellas, desplegando a su vez tres voces en off que explican historias representativas de diferentes etapas en la historia de las migraciones en Barcelona. La tercera y última postal es de 2001 y enlaza con el epígrafe anterior: la voz del marroquí Yidir Ikabouren lee su diario personal para contar al espectador su experiencia en la movilización de la iglesia del Pi. Yidir describe buena parte del encierro y cómo logró su regularización después del mismo, lo cual le permitió "un año y tres meses más tarde de haber cruzado el Estrecho en patera" (14'29"), acceder a su primer trabajo de peón de albañil en condiciones de ciudadano regular. Se trata de la secuencia que cierra el cortometraje, proponiendo un fuerte contraste entre la condición de turista (plano visual) y la condición de migrante (plano sonoro), siguiendo un montaje de planos de turistas fotografiándose frente a la misma iglesia y mostrando de esta manera cómo un escaparate turístico por excelencia es también un lugar de memoria de las luchas por derechos.

La primera postal de las tres se ubica temporalmente alrededor de 1956, cuando Ramón Molina fue destinado como trabajador de RENFE a Barcelona. El protagonista estuvo alojado en las llamadas patronas: habitaciones vacías en casas particulares que servían para alojar a recién llegados, a veces en régimen de pensión completa. Ramón también viajaba mucho de Madrid a Barcelona y, conocedor del mecanismo de deportaciones vigente en aquel momento, protegía a las familias viajeras con la siguiente recomendación: "no bajaros ni en la estación de Francia ni en Paseo de Gracia que os trincan" (5’01"). El peligro de ser retornadas a sus lugares de origen ipso facto era mayor en esas estaciones que en otros destinos con un control más laxo, como Sitges. De hecho, Ramón vio la misma escena repetida en varias ocasiones: las familias sin papeles de la época, bien cargadas de equipaje, eran detenidas en un rincón, prolegómeno previo a su expulsión de la ciudad. La narración de la voz en off coincide, a nivel visual, con un plano secuencia que abarca un tramo del recorrido de un ferrocarril que finaliza precisamente en la estación de Francia, un

18 Ibidem, p. 102. 
lugar de llegada de las migraciones pretéritas inmortalizado icónicamente en el documental sobre emigrantes españoles y periferias Largo viaje hacia la ira (Llorenç Soler, 1969).

La segunda postal relata la situación de una inmigrante latinoamericana alrededor de 1988: Griselda Martínez Vico. Los espacios de la ciudad que rememora son el Barrio Chino (actual Raval) de la heroína, donde ella residía, y la Rambla, esquina con calle Ferran, donde existe todavía hoy el buzón en el que se encaramaba para avistar la llegada de policías y avisar gritando "¡agua!” a sus compañeros. El trabajo que llevaba a cabo era la venta ambulante ilegal, ya que, en aquel entonces, igual que hoy, resultaba muy complicado encontrar un trabajo debido a la condición de sin papeles: "no sé si era menos difícil que ahora encontrar un trabajo, pero era muy difícil" (8'29").

Resulta imposible no encontrar ecos y afinidades iconográficas de tal relato con la situación actual de los manteros que veremos en el epígrafe posterior. Sin embargo, antes de abordar tal cuestión, resulta importante reflexionar acerca de la forma de representación estética elegida por el director de Mapas migrantes: no enseñar el rostro de las y los protagonistas, o de quienes colaboraron en anónimos actos de resistencia, y evocar así sus vivencias a partir de voces y espacios. Con ello configura una poética de la memoria que trata de evidenciar la permanencia de las y los migrantes invisibles en la ciudad, a pesar de que muten los rostros y las procedencias, así como también las múltiples formas de solidaridad antifronteras que tienen lugar en lo social.

En cierta manera, el relato que propone David Batlle se parece a las experiencias psicogeográficas de los situacionistas: en espacios cualquiera, si bien hoy altamente turistizados (como una iglesia, la Rambla o la Estació de França), las emociones y pensamientos de las personas que los atraviesan dependen de la experiencia concreta, muy distinta si el viaje está hecho con intenciones ociosas o si se plantea como una fuga política. La estética elegida apuesta por la suma de voz e imagen que articula los relatos. Dicho de otra manera, crea imágenes que se forman en la mente del espectador, derivadas de unos recuerdos personales que son inseparables del escenario urbano. Significativamente, las escenas que describen -encierros, redadas y venta ambulante- todavía hoy se continúan repitiendo.

\section{El gesto de levantar la manta}

Siguiendo con la reflexión sobre la relación entre turismo y migraciones que se viene apuntando, resulta importante mencionar que el rodaje de Vicky, Cristina, Barcelona (Woody Allen, 2008) trajo consigo un debate importante a nivel de ciudad. El consistorio socialista invirtió un millón de euros en la producción de la película, justificando que era la mejor y más rentable inversión posible en publicidad turística que se podía hacer en aquel momento. La promoción de los encantos urbanos (principalmente el patrimonio modernista que miran con fascinación las dos norteamericanas protagonistas), fue concebida desde la óptica del gobierno local como un perfecto spot que llegaría a millones de espectadores, convirtiéndolos así en potenciales turistas. Premios como el Óscar de Penélope Cruz a la mejor actriz de reparto (2008) o el Globo de Oro a la mejor comedia (2009) supusieron la confirmación de las mejores expectativas de los políticos impulsores: el filme de Allen recaudó 96 millones de dólares en taquilla, lo que significó una enorme visibilidad del escenario barcelonés.

En mi trabajo de tesina definí la película como la culminación del llamado Cinemarca Barcelona, un concepto que sirve para expresar cómo el cine ha sido utilizado para promocionar la Ciudad Condal en circuitos internacionales ${ }^{19}$. Previamente se habían rodado cinco películas en las que el espectador se podía identificar con un turista extranjero o un recién llegado, deslumbrado ante la arquitectura y los principales

\footnotetext{
19 Joan Miquel GuAL, "La representació de Barcelona en el cinema contemporani. Cinemarca Barcelona, espectadors turistes, paisatges de no ficció", Tesina, Barcelona, Universitat Pompeu Fabra, 2010.
} 
ítems que aparecen en cualquier guía turística ${ }^{20}$. Si bien quizá no era la intención de los directores, sus obras resultaron funcionales a la hora de vender la ciudad como marca y producto cultural en el exterior, mediante un relato que embellece y resalta, cual si fuera una operación planificada de mercadotecnia urbana, determinados aspectos de la ciudad en detrimento de otros más problemáticos. De ahí el concepto de cine-marca.

Por otra parte, Biutiful (Alejandro González Iñarritu, 2010) mostró una cara mucho más amarga del mismo lugar. Entre las muchas escenas turbias que expone, una muy habitual y real muestra a manteros de piel negra corriendo Rambla arriba, perseguidos por la policía. Sin lugar a dudas, la dureza de la vida de los pobres racializados (la película también aborda problemáticas relativas a los almacenes chinos ubicados en Badalona y Sant Adrià de Besós) no debió resultar nada seductora para unos gobernantes poco interesados en enseñar en el exterior una cara distinta de una ciudad sobrecargada de conflictos raciales, que no tienen cabida en la marca que se quería difundir. Si bien el tono de la película no es realista, plantea una serie de cuestiones que afean la imagen dominante existente, supuestamente tolerante con todos y multicultural, generando serias dudas acerca del escaparate aproblemático a nivel social y sin desigualdad económica que promueve el imaginario turístico vigente.

En el plano de la no ficción, Nosotros, los negros afronta el tema de los manteros algunos años después de Biutiful, cuando este colectivo encarnó una de las principales crisis con las que ha tenido que lidiar el llamado "municipalismo del cambio" liderado por la alcaldesa Ada Colau. Una serie de enfrentamientos con la policía provocaron la circulación, en medios de comunicación masivos, de la imagen de agresiones físicas a las fuerzas policiales por parte de algunos vendedores de calle. Sin ir más lejos, el periódico $L a$ Vanguardia, referente mediático catalán de signo ideológico claramente antagonista con el nuevo municipalismo, publicó varias portadas con el objetivo de transmitir una imagen de fuerte desorden público y señalar, al mismo tiempo, la contradicción de un gobierno progresista que ejerce represión sobre un colectivo vulnerable, contrariamente a su ideología y programa político.

En el mismo contexto, el semanario de izquierdas La Directa publicó un reportaje histórico titulado "Barcelona ja criminalitzava la venda ambulant als anys trenta" ${ }^{21}$. En el mismo, una fotografía muestra a varios agentes de la guardia urbana obligando a vendedores a deshacerse en una alcantarilla del pescado que trataban de vender a pie de calle. Esta imagen sirve para criticar la dificultad que tienen los pobres para sobrevivir a las crisis ocurridas en diferentes momentos históricos, a pesar de la existencia de gobiernos progresistas. Sin lugar a dudas, permite establecer una continuidad iconográfica entre pasado y presente (fig. 1).

A nivel cinematográfico, la referencia del título del filme es clara: Moi, un noir (Jean Rouch, 1959), docu-fiction primigenia del cine etnográfico que retrataba la vida de tres negros (Tarzan, Eddie Constantine y Robinson) en Treichville (un barrio situado en Abidjan, la capital económica de Costa de Marfil), a la búsqueda desafortunada de trabajo escaso y siempre mal pagado. La presencia abusiva del hombre blanco, el colonizador en posesión del dinero, se erige como un claro símbolo de la vida urbana africana del momento. Nosotros, los negros plantea una transposición contemporánea de ese relato en la Barcelona actual. De manera similar al film de Rouch, la plena afinidad de los directores con el sujeto representado salta a la vista debido a la calidad de las entrevistas y a la confianza lograda para enseñar ante la cámara sus vidas y sus rostros, a pesar del peligro evidente que representa para sí mismos la visibilidad en una pantalla debido a su condición de sin papeles. Por otra parte, el desplazamiento que se produce entre las películas no solamente es de coordenadas espacio-temporales, sino de calado político: el nosotros que articu-

20 Souvenir (Rosa Vergés, 1994); Todo sobre mi madre (Pedro Almodóvar, 1999); Tardes de Gaudí (Susan Seidelman, 2001); Una casa de locos (Cédric Klapisch, 2002); Manuale d'amore 2 (Giovanni Veronesi, 2008).

21 "Barcelona ya criminalizaba la venta ambulante en los años treinta". Roger CosTA PUYAL, "Barcelona ja criminalitzava la venda ambulant als anys trenta", Setmanari La Directa, 395 (2015), pp. 22-23. 


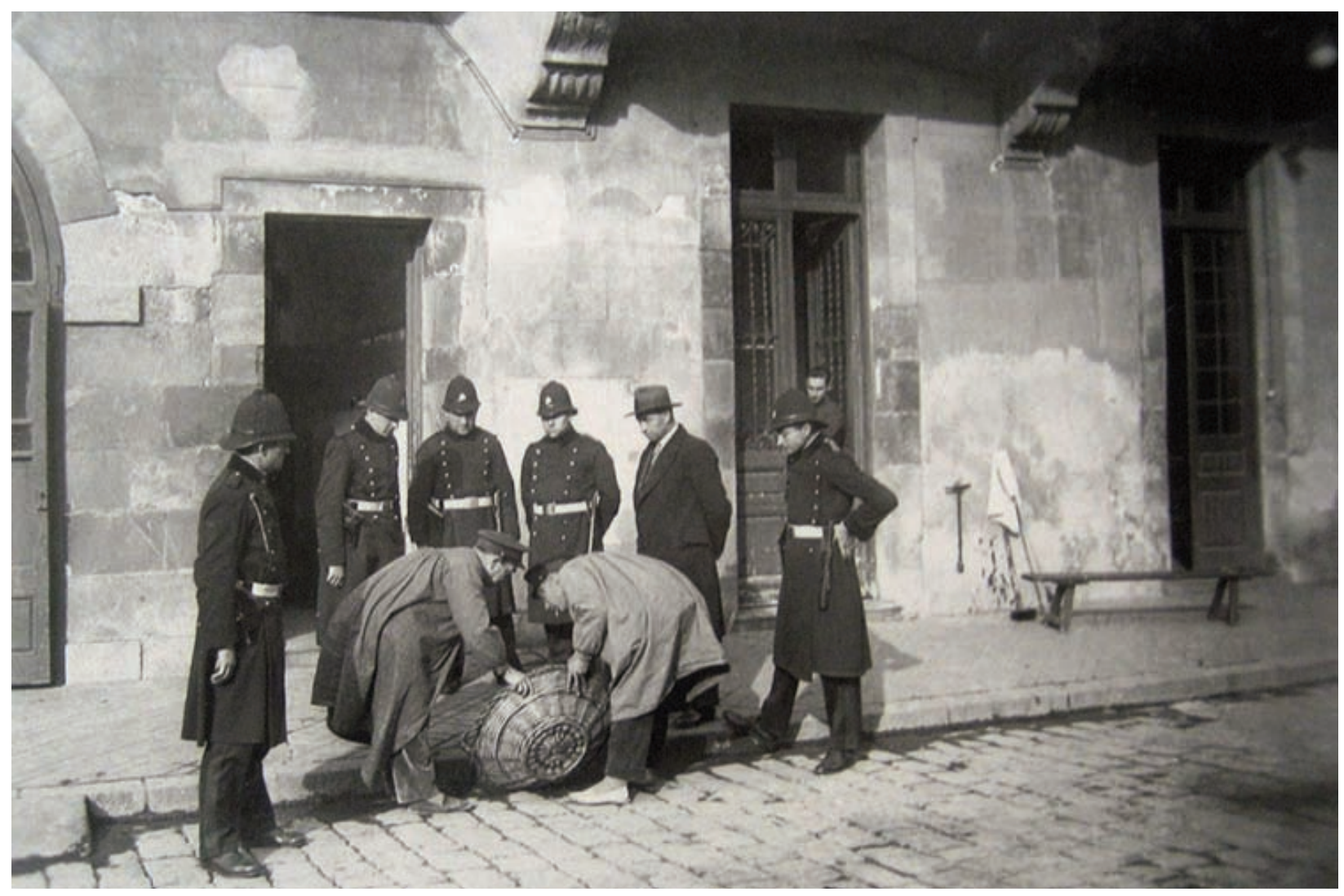

Fig. 1. Autor desconocido, Vendedores ambulantes obligados a tirar su mercancía por la policía local, alrededor de 1932, fotografía, 700x500 mm, Barcelona, Arxiu Fotogràfic de Barcelona.

la el título plantea la existencia de un sujeto colectivo en ciernes, frente a la fragmentación de relatos individuales de "un negro" cualquiera de los muchos existentes en las periferias africanas; el nosotros denota persistencia de la herida colonial en el cuerpo de los negros, así como también un proceso de auto-organización para sobrevivir colectivamente en el centro de una ciudad global cuyo espacio público está dominado por hordas turistas. Estos últimos son clientes potenciales tanto de los manteros como de buena parte de los negocios nuevos y viejos de la ciudad, algunos de ellos regentados por vendedores organizados en plataformas que persiguen erradicar de la calle una actividad que consideran competencia ilegal y desleal. De esta manera, se fija ideológicamente un nosotros político que, para determinada población local, significa un ellos peligroso. De hecho, una secuencia muestra dos personas de la calle que increpan a los vendedores ambulantes, acusándoles no solamente de no pagar impuestos y robar clientes a las tiendas "honradas", sino también de haber emigrado para venir a sembrar el desorden.

En la película ocupa una importancia central la deconstrucción de un hecho cuya imagen sirvió para acusar y encarcelar a uno de los vendedores, llamado Sidil. Dicha imagen supuestamente demostraba la agresión del mantero a un policía local. El frame que se publicó en los media, como prueba del crimen, descongelado en el documental, permite visionar el antes y el después de lo ocurrido, dejando a juicio del espectador si la agresión era tal y, en cualquier caso, si resultaba merecedora o no del castigo infligido. Desde la perspectiva de los directores, la secuencia en cuestión se incluye en el relato con la intención de criticar un sensacionalismo criminalizador con fines de pánico moral, muy alejado de lo que sería una información imparcial.

La película finaliza en las puertas de la prisión Modelo, donde Sidil fue encerrado después de los hechos, en una manifestación que exige tanto la libertad del detenido como el derecho a permanecer y 
ganarse la vida trabajando en cualquier ciudad del mundo. El cortometraje invita a pensar, a través del diálogo implícito con Jean Rouch, en la condición de muchas personas de piel negra tanto en sus países de origen, para nada desprovistos a día de hoy de rasgos de dominación neocolonial, como en los lugares de llegada. Nosotros, los negros supone, contando con el consentimiento y la aceptación de los representados, una aportación al giro decolonial a partir de una alianza ética que trata de borrar la frontera entre quien habla -los sujetos directores- y quien es mostrado -el objeto de la película, los manteros-, mediante un relato en que los primeros se ponen al servicio de los segundos.

\section{Rastros coloniales en la Barcelona del "Procés independentista"}

En agosto de 1936 fue derribada la estatua de Antonio López, primer marqués de Comillas (fig. 2). Al final de la Guerra Civil, el monumento fue restituido y permaneció hasta el 4 de marzo de 2018, cuando el ayuntamiento decidió retirarlo después de movilizaciones ciudadanas y estudios académicos que señalaban claros indicios de ejercer el esclavismo por parte del homenajeado. Así, una misma imagen decolonial tuvo lugar en dos momentos completamente distintos de la historia de la ciudad.

CC13 rastrea los signos de colonialidad que persisten en la arquitectura urbana. Desde la icónica estatua a Colón, pasando por la misma plaza dedicada a Antonio López o el monumento a Joan Güell i Ferrer, destacado líder intelectual contrario al abolicionismo de esclavos. También describe la historia de varios edificios construidos fruto de la riqueza generada durante siglos pasados en ultramar: por ejemplo, el Palau de la Virreina o el Hotel Colonial $^{22}$. La obra de Ortiz y Quiroga no se puede considerar ni mucho menos un documental informativo o histórico. La crítica ideológica de los tres dispositivos que forman la película, basados en la performatividad y la entrevista, se construye en relación a la Diada del 11 de septiembre de $2013^{23}$, cuando se celebró la Via Catalana, una cadena humana en que participaron más de 1.600 .000 personas dándose la mano, atravesando 87 municipios catalanes ubicados en la

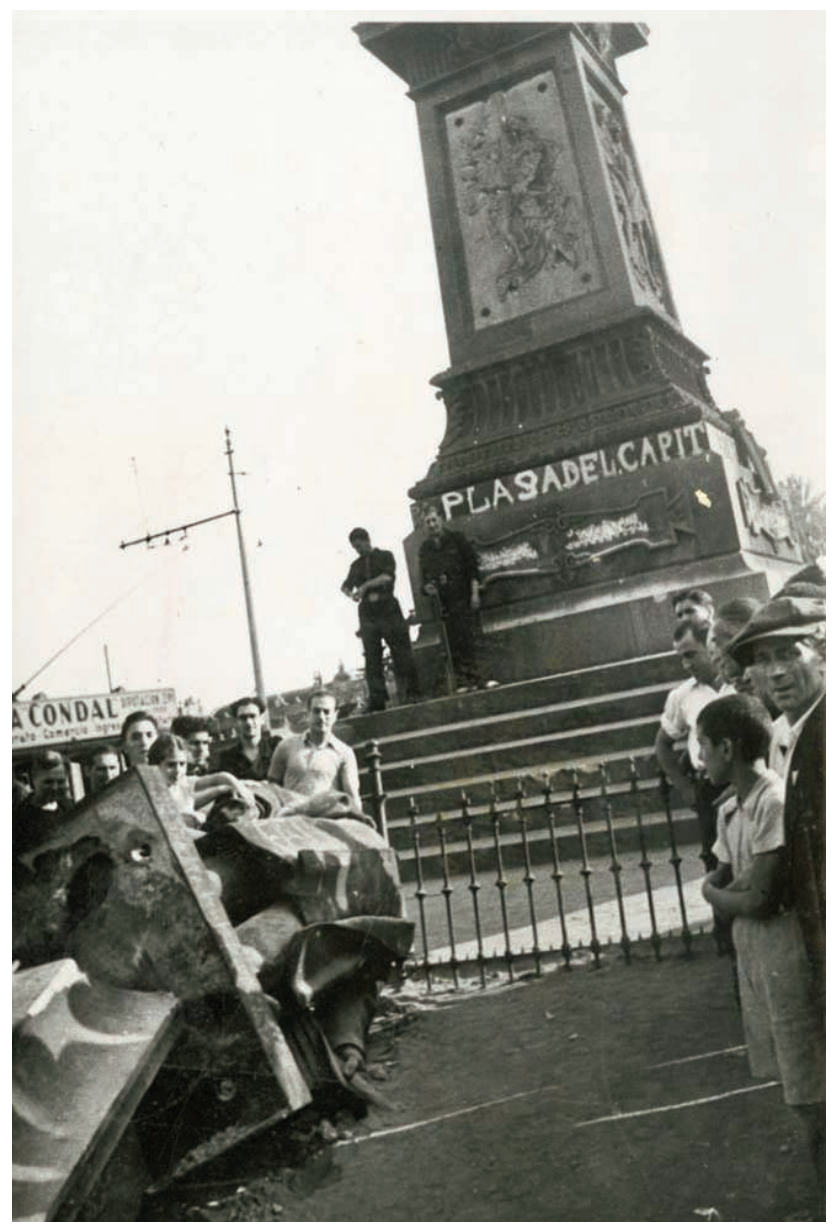

Fig. 2. Autor desconocido, Derrocamiento de la estatua de Antonio López, 1936, fotografía, 671x960 mm, Amsterdam, Instituto Internacional de Historia Social.

\footnotetext{
22 Este hotel fue antiguamente la sede del Banco Colonial, creado para financiar operaciones militares en Cuba durante el siglo XIX, y es hoy un hotel que forma parte del circuito turístico de mayor poder adquisitivo.

${ }^{23}$ La Diada es la fiesta nacional de Catalunya. Cada 11 de septiembre se conmemora la defensa de Barcelona en 1714. Ese día las tropas de Felipe V de Borbón ganaron la Guerra de Sucesión, derrotando las tropas de la Corona de Aragón y suspendiendo las instituciones de autogobierno y libertades civiles catalanas. Desde el año 2012, cuando se inició el llamado "Procés", los actos de la Diada tienen un marcado cariz político en favor de la independencia de Catalunya.
} 


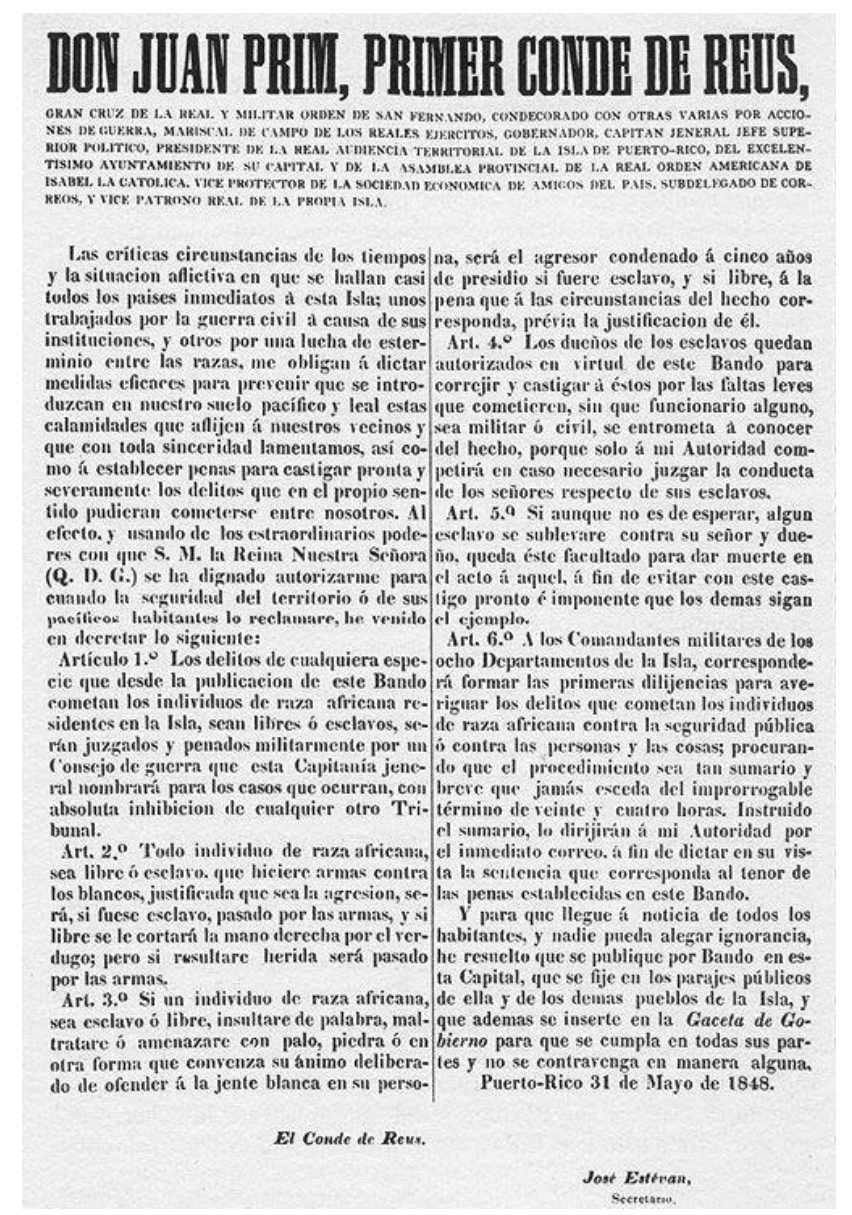

Fig. 3. Código Negro (Bando del general Prim), 1848.

antigua Vía Augusta, abarcando desde Vinarós (Castellón) hasta El Voló (sur de Francia). En este contexto, un primer dispositivo performativo del cortometraje consiste en repartir un bando del General Prim con el Código Negro; este documento de mediados del siglo XIX ordenaba de manera explícita la masacre indiscriminada de esclavos para frenar cualquier atisbo de levantamiento en la colonia española de Puerto Rico. Por ejemplo, su artículo 5 afirma: "Si, aunque no es de esperar, algún esclavo se sublevare contra su señor y dueño, queda este facultado para dar muerte en el acto a aquel, a fin de evitar con este castigo pronto e imponente que los demás sigan ejemplo" (fig. 3).

La repartición del escrito evidencia una contradicción política clara: tiene lugar a manos de Daniela Ortiz frente a una estatua que puede ser leída como un signo de barbarie, que forma parte de un legado colonial que no ha sido puesto en cuestión en una ciudad de la antigua metrópolis. La imagen de una multitud frente al monumento, participando en una acción de protesta precisamente contra la opresión del Estado español, señala el desconocimiento de la figura histórica de Prim, así como también la elección casual del lugar sin ni tan siquiera problematizar su contenido simbólico.

El segundo dispositivo es de tipo verité o interactivo. El activista entrevistado Mamadou Kerabá Dramé (Federació Panafricanista de Catalunya) reconoce el derecho a la autodeterminación de todos los pueblos y naciones, si bien deja claro que le resulta difícil compartir una lucha de liberación nacional como la catalana, cuando la ciudad donde vive sigue llena de tantos signos que homenajean el esclavis- 
mo y el pasado colonial. En su discurso señala también la existencia ignominiosa, no mucho tiempo atrás, del "negro de Banyoles"24. Kerabá dialoga con unas declaraciones del presidente catalán de entonces, Artur Mas, en las que compara la Via Catalana con la Marcha de los Derechos Civiles de 1963 (conocida también como la Marcha en Washington por el trabajo y la libertad), cuando alrededor de 300.000 personas protestaron contra la situación de racismo y segregación existente en Estados Unidos cien años después de la Proclamación de Emancipación firmada en 1863. Kerabá recomienda salvar algunas distancias imprescindibles entre un acontecimiento y otro debido a niveles de opresión que no resultan comparables en cuanto a magnitud. Su discurso no deja lugar para las dudas: la situación de la población catalana actual se encuentra bien lejana de la de la población negra estadounidense de mediados del siglo XX.

Por último, el tercer dispositivo ocupa un lugar intermedio entre el modo interactivo y el performativo. Daniela Ortiz pregunta a varias personas asistentes a la Diada acerca de la figura histórica de Cristóbal Colón, que nadie cuestiona de manera profunda o radical. La existencia del monumento, el pasado colonial y el presente movilizado en favor de la autodeterminación no parecen presentar ninguna contradicción a los entrevistados. De hecho, aprecian el interés turístico del monumento, valorándolo como una parte querida y aceptada de la propia identidad local ${ }^{25}$. A modo de contraposición dialéctica, los rótulos finales de la película conectan el cierre de las fronteras en Europa y las muertes que provoca, principalmente de personas que provienen de países que en el pasado fueron colonizados y esclavizados por naciones europeas.

\section{Contrainformación, islamofobia y redadas}

El periódico Diagonal comenzó en 2010 una campaña para señalar la existencia de redadas racistas en Madrid, denunciando así el funcionamiento casi invisible de check-points urbanos orientados a detener personas migrantes indocumentadas para expulsarlas del país ${ }^{26}$. Olmo Calvo, Edu León y otros fotoperiodistas tuvieron problemas en varias ocasiones con agentes de la Policía Nacional, al documentar y hacer visibles algunos controles que estaban teniendo lugar en estaciones de metro y en la misma calle. En Barcelona, la campaña "Enredadas" también persiguió la finalidad de denunciar que se estaban llevando a cabo identificaciones y detenciones policiales en la calle, muchas veces en lugares tan céntricos como La Rambla del Raval $^{27}$. Mostrar un pañuelo rojo en el momento de la redada fue método utilizado para visibilizar una situación que se producía de manera discreta, pudiendo pasar desapercibida para la población local, los turistas o cualquier persona no racializada. La redada que tuvo mayor impacto televisivo y mediático se produjo en 2008, en una mezquita y una pastelería islámicas del Raval. Fue mostrada muy insistentemente por varios medios de comunicación durante muchos días consecutivos.

Otra de las películas-voz que aquí se analizará denuncia cómo una acusación falsa de terrorismo llevó a 11 vecinos del Raval a la cárcel. Rastros de Dixán fue difundida en 2009 junto con un libro con textos de análisis de título homónimo y un blog. La intención de los colectivos impulsores era contrainformativa: desmontar una versión oficial, considerada como un signo de islamofobia, que sirvió para privar de libertad durante siete años a los acusados de intentar perpetrar un atentado terrorista. La comunidad pakis-

\footnotetext{
24 Si bien hablaremos más adelante sobre esta cuestión, aquí cabe decir que el "negro de Banyoles" fue una persona disecada que se mantuvo expuesta en el Museu Darder de Banyoles (Girona), entre 1916 y el año 2000, cuando fue repatriado a Botswana después de protestas internacionales.

$25 \mathrm{Si}$ bien no se puede afirmar que la parte entrevistada represente el todo o el conjunto de opiniones de todas las personas asistentes, sí que queda clara una cuestión: la oposición a la existencia del monumento es, a día de hoy, prácticamente inexistente.

26 "Dos años de cárcel por documentar una redada racista en Lavapiés", Diagonal, 29 de enero de 2016 [en línea] https://www.diagonalperiodico.net/libertades/29184-dos-anos-carcel-por-documentar-redada-racista-lavapies.html [Consulta: 15 de mayo de 2019].

27 Estamosenredad@s blog http://estamosenredadas.blogspot.com/ [Consulta: 15 de mayo de 2019].
} 

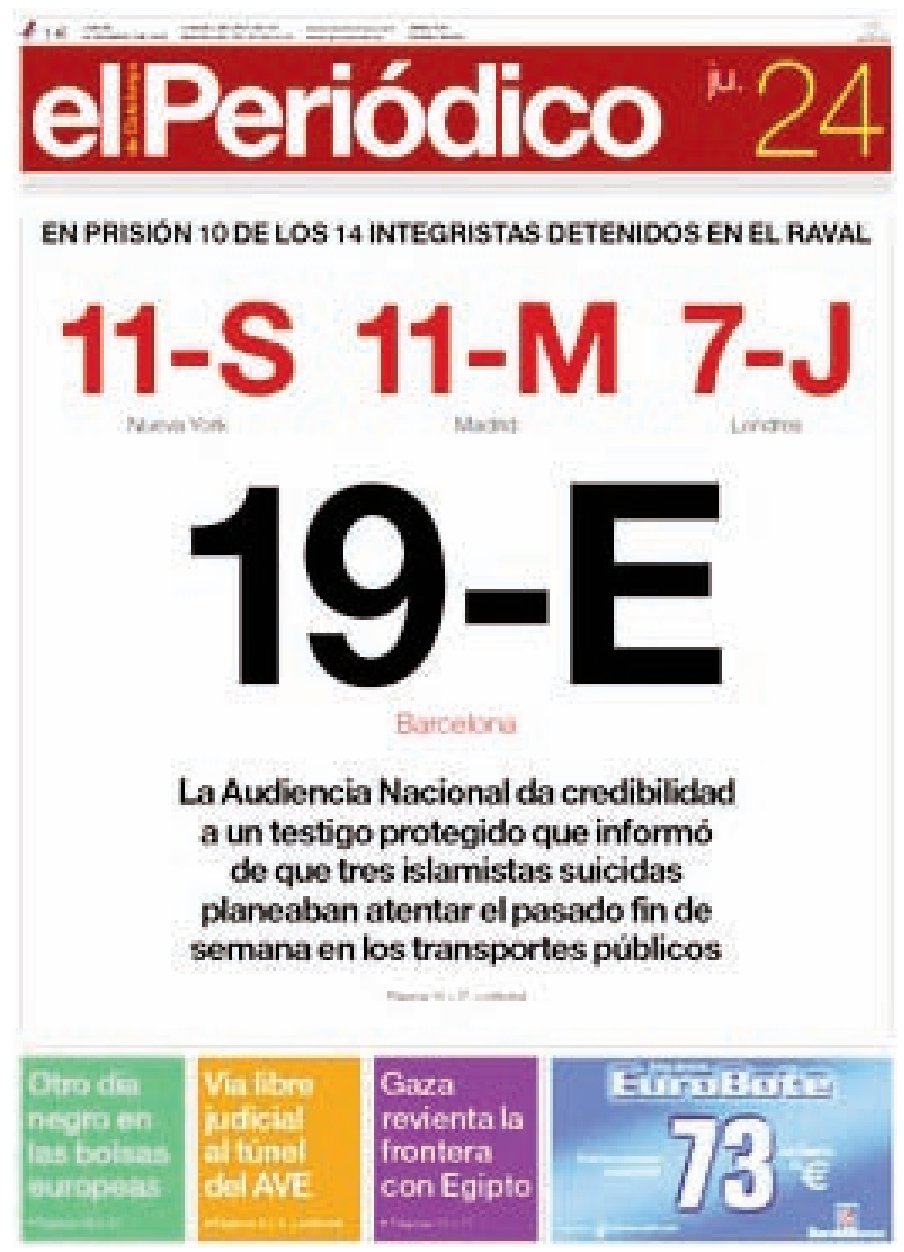

Fig. 4. Portada de El Periódico, jueves 24 de enero de 2008.

taní y un grupo de periodistas y activistas -vinculados al Raval, a la editorial Virus y a las luchas antirracistas-, pretendieron también frenar el racismo social, el miedo y el sentimiento de amenaza que emergieron entonces, señalando la magnificación mediática causada por el bombardeo de noticias que señalaba la supuesta existencia de un enemigo interno muy peligroso.

El primer punto de ataque del proyecto Rastros de Dixán fue, sin lugar a dudas, la portada de El Periódico, publicada el jueves 24 de enero de 2008 (fig. 4). En la misma, se podían leer las siglas 11-S, 11-M, 7-J -que hacían referencia a los atentados de Al Qaeda en Nueva York, Madrid y Londres respectivamente-, y en una tipografía mucho mayor y destacada en el centro de la plana, 19-G (la "G" es la sigla de "Gener", que significa enero en catalán). De esta manera, se equipararon atentados consumados que causaron la muerte y el dolor de muchas personas a un ataque terrorista que no había tenido lugar. El escándalo y la generación de pánico moral fueron mayúsculos entre la población local. Por ello, resulta útil recordar las palabras que aparecen en Rastros de Dixán:

[...] uno de los objetivos de este libro no es exactamente defender la honorabilidad de los musulmanes, sino su complejidad como colectivo: que un musulmán pueda ser un delincuente común, tanto como un católico, un protestante, un judío o un adepto al budismo. Que pueda atracar un banco, estafar a Hacienda, ser un político corrupto o un ministro irresponsable sin que eso lo convierta automáticamente en un sospechoso de terrorismo islámico [...] El segundo objetivo de este libro es, precisamente, mostrar cómo todo el aparato intelectual desplegado por 
think tanks, medios de comunicación, "opiniones autorizadas", fuentes policiales... es pensamiento mágico que no se atiene a razones o a hechos comparables, sino que sirve para mantener el imaginario adecuado para un clima de terror y alarma social ${ }^{28}$.

Por otra parte, resulta necesario también remarcar un texto que aparece en la última página del libro, acerca de la falsedad de algunas noticias aparecidas en su día, sin que haya habido ningún tipo de reacción reparadora al respecto:

Este libro fue impreso a finales de mayo de 2009; aproximadamente 1 año y 4 meses después de las detenciones de 9 ciudadanos pakistaníes y 2 indios, acusados de preparación de un supuesto atentado contra el transporte público en Barcelona. En el momento en que se publica Rastros de Dixán, la mayoría de noticias difundidas en su día han sido demostradas como falsas por la propia instrucción judicial. Ninguna de ellas ha sido desmentida ni rectificada por los medios responsables ${ }^{29}$.

El documental está construido sobre la idea de un régimen de verdad formado por una red que abarca desde las declaraciones del entonces Ministro de Interior Alfredo Pérez Rubalcaba, o miembros de la Audiencia Nacional como el juez Garzón, hasta informes del Centro Nacional de Inteligencia o una cobertura informativa en que participan prácticamente todos los medios de comunicación y agencias de noticias, ofreciendo lecturas sesgadas de la situación e imágenes repetitivas de la redada que se produjo en la mezquita. El mecanismo de deconstrucción de la verdad construida está en el énfasis puesto, mediante el montaje, en la repetición cíclica de diferentes mensajes que circularon repetidamente sobre hechos manifiestamente falsos: 1. Que se encontraron explosivos; 2. Que se desarticuló una célula terrorista instalada en el Raval; 3. Que se había evitado un atentado.

Siete años después, en julio de 2015, el periódico catalán $A R A$ pidió reparación periodística de los hechos en un artículo de opinión, propuesta que cayó en saco roto ${ }^{30}$. Más allá, en una rueda de prensa que tuvo lugar después de conocerse la falsedad del testimonio protegido, miembros de la editorial Virus, la comunidad pakistaní y el semanario La Directa reclamaron el retorno de los deportados (todos los detenidos excepto dos) y la liberación inmediata del vecino del Raval que todavía seguía encarcelado entonces. Como en el caso de las armas de destrucción masiva argumentado por Bush para invadir Irak, en el Raval barcelonés se coló el nuevo orden penal mundial a través de la invención de un posible atentado, ante el cual no existió presunción de inocencia.

Dicho esto, resulta importante señalar que en el verano de 2017 tuvo lugar un atentado en el centro de la ciudad, sin que los cuerpos de seguridad tuviesen la previsión ni el control que trataron de escenificar públicamente algún tiempo atrás. En este caso, la captación de quienes perpetraron los atentados, todos ellos ciudadanos con nacionalidad española, la llevó a cabo una persona perfectamente integrada. A este respecto resulta importante destacar que las redadas racistas no han funcionado como mecanismo útil para revelar la existencia de redes proto-terroristas arraigadas en el territorio. Por ello, el debate abierto por Rastros de Dixán sobre islamofobia y la construcción mediática de la verdad y la sospecha sigue vigente. Las redadas -a veces vestidas de espectacular acción antiterrorista, a veces de invisible control rutinariodan forma a una iconografía que prueba otra dimensión de la experiencia de frontera cotidiana y la colonialidad del poder en la actualidad.

28 VV. AA, Rastros de Dixán. Islamofobia y construcción del enemigo en la era post 11-S, Barcelona, Virus, 2009 , p. 9.

29 Ibidem, p. 144.

30 Àlex GUTIÉRREZ, "Els 11 del Raval també mereixen reparació periodística” (Los 11 del Raval también merecen reparación periodística), ARA, 4 de julio de 2015 [en línea] https:/www.ara.cat/premium/Raval-tambe-mereixen-reparacio-periodistica_0_1388261183.html [Consulta: 20 de mayo 2018]. 


\section{Cadáveres repatriados: entre el negro de Banyoles e Idrissa Diallo}

La última iconografía que se presentará en este artículo tiene relación con cadáveres repatriados, a partir de los dos casos citados en el título de este epígrafe, que consideraremos, para empezar, significativos de la mutación del racismo biológico en racismo institucional dentro de los contextos español y catalán. Hasta el año 1999 se pudo ver en el Museu Darder de Banyoles (Girona), en concreto en la sala dedicada al hombre, la figura de un bosquimano disecado. Es decir, la ciudad famosa por su lago -que acogió las carreras de remo en los Juegos Olímpicos de 1992-, también fue conocida por albergar, a finales del siglo XX, una pieza de taxidermia propia de un museo del siglo XIX. En 1997 el espacio televisivo 30 Minuts dedicó un reportaje titulado "L'home dissecat" (El hombre disecado) a la polémica que suscitó un médico haitiano, con la piel negra y residente en Banyoles, que había emprendido algunos años antes una cruzada para eliminar el objeto de contemplación museística, considerando su existencia una forma de racismo completamente denigrante ${ }^{31}$. Alphonse Arcelin envió cartas a diestro y siniestro a todas las organizaciones y países africanos susceptibles de protestar y actuar contra la situación. El reportaje, además de reconstruir la historia del negro disecado con todo lujo de detalle histórico, describe detalladamente el marco del conflicto diplomático que ocasionó la polémica: la Organización de Países Africanos estaba en ese momento a punto de emitir un posicionamiento político contrario a la exposición del cuerpo.

Descontando a Arcelin, sorprende hoy que los testimonios incluidos no vean problemática la exposición de la figura. El reportaje refleja la existencia de cierto consenso favorable a su presencia en el pueblo de Banyoles, un consenso que alcanzaría también supuestamente a la población negra residente allí en aquel momento ${ }^{32}$. Por si fuese poco, se podría decir que la denuncia del médico generó lo que hoy en día se conoce como efecto Streisand, es decir, aumentó el interés por asistir al museo debido al morbo de contemplar con los propios ojos la pieza en cuestión ${ }^{33}$.

Un tal Mulibahan (Harmonia Carmona, 2001) es una no ficción posterior que explica todas las peripecias de la repatriación del "negro de Banyoles" a su país de origen, después de haber sido conservado durante más de 170 años en el extranjero. Mencionar dicho conflicto resulta útil como introducción para hablar de Idrisa, crónica de una muerte cualquiera, que consideramos una obra importante debido a dos motivos fundamentales. En primer lugar, se trata de un trabajo sobre una cuestión apenas tratada en la no ficción audiovisual: la existencia del Centro de Internamiento de Extranjeros (CIE) de Barcelona, ubicado en el barrio Zona Franca. Podemos definir el CIE como una prisión étnica, un mecanismo de frontera interna dedicado a la detención de personas migrantes indocumentadas. Ha sido denunciado reiteradamente por organizaciones en favor de derechos humanos debido a una gestión opaca del centro que ha supuesto que sea comparado en muchas ocasiones con Guantánamo. En segundo lugar, la obra investiga un caso de muerte no aclarada en el CIE, cuyo espacio está custodiado por la Policía Nacional. Se trata de una muerte (o asesinato) que, a día de hoy, no tiene ningún responsable directo conocido.

\footnotetext{
31 El reportaje cuenta con entrevistas a especialistas en Historia Natural que dejan claro que los bosquimanos son la estirpe humana existente más antigua sobre el planeta tierra. Explican también que cuando Alemania "descubrió" Botswana en la primera mitad del siglo XIX no se consideró científicamente humanos a los bosquimanos, sino una raza animal aparte. De hecho, la exposición de figuras similares resultaba habitual a finales del siglo XIX y principios del XX en la sección de animales de los museos naturales, si bien tal tendencia fue en declive a lo largo del siglo XX y a medida que el racismo biológico fue dejando de tener vigencia en el campo de la ciencia. Sin embargo, el negro de Banyoles llegó allí en 1916 para permanecer hasta 1999, cuando fue repatriado.

32 El relato de la voz en off y de algunos entrevistados así lo afirma, pero, sin embargo, no aparece ninguna persona de piel negra comentando nada al respecto.

33 "El efecto Streisand es un fenómeno de internet en el que un intento de censura o encubrimiento de cierta información fracasa o es contraproducente, ya que esta acaba siendo ampliamente divulgada o reconocida de modo que recibe mayor visibilidad de la que habría tenido si no se la hubiese pretendido acallar". Ver "Efecto Streisand", Wikipedia [en línea] https://es.wikipedia.org/wiki/Efecto_Streisand [Consulta: 20 de mayo 2018].
} 
Metromuster impulsó, junto con otras organizaciones por el derecho a la libertad de movimiento y el cierre de los CIEs, la repatriación del cadáver de Idrissa Diallo. De hecho, llevó a cabo una exitosa campaña de micromecenazgo que recaudó más de $12.000 €$, destinados íntegramente a costear el traslado de los restos mortales a su pueblo natal. Diallo previamente había sido enterrado en el cementerio de Montjuïc en una tumba anónima, sin ni tan siquiera informar al país de origen acerca de su muerte. Por ello, varias organizaciones sociales y cooperativas llevaron a cabo una ardua tarea diplomática que correspondería a los cuerpos del Estado, hecho que resulta un considerable cambio de paradigma en términos de sensibilidad antirracista en un lugar, Catalunya, que, como se ha dicho más arriba, no hace tanto tiempo exponía sin problemas un negro disecado, siendo famosa y objeto de cierta guasa la cuestión de su repatriación ${ }^{34}$.

Por otra parte, el documental señala la irresponsabilidad existente en la gestión de una muerte que nada tiene que ver con el pasado remoto, sino con el presente más actual: el elevado número de fallecimientos causados directamente por el régimen de fronteras. En la mayor parte de los casos, las familias no tienen derecho ni tan siquiera al duelo. En este sentido, el trabajo de Metromuster se puede alinear con la postura política y filosófica expresada por Judith Butler, que busca reconocer la precariedad de toda vida humana, precondición necesaria para eliminar la distinción existente a día de hoy entre unas vidas que merecen ser lloradas y otras que no; dicho de otra manera: tanto la cooperativa como la pensadora norteamericana reivindican la necesidad de establecer normativas que acaben con una situación política que produce muertes de primera y de segunda, hecho que se traduce en el silencio y el olvido para unos, y en rituales de Estado y atención mediática para otros:

Para que las poblaciones se vuelvan susceptibles de ser lloradas no es necesario conocer la singularidad de cada persona que está en peligro o que, seguramente, ya lo ha estado. Lo que queremos decir es que la política necesita comprender la precariedad como la condición políticamente inducida que negaría una igual exposición mediante una distribución radicalmente desigual de la riqueza y unas maneras diferenciales de exponer a ciertas poblaciones, conceptualizadas desde el punto de vista racial y nacional, a una mayor violencia. El reconocimiento de la precariedad compartida introduce unos fuertes compromisos normativos de igualdad e invita a una universalización más enérgica de los derechos, que intente abordar las necesidades humanas básicas de alimentación, cobijo y demás condiciones para poder persistir y prosperar ${ }^{35}$.

Por ello, el documental Idrissa... sobre la repatriación de un cadáver que ha dejado de ser anónimo es una acción de tipo decolonial. La mutación semántica entre la repatriación del negro de Banyoles y la repatriación de Idrissa resulta inequívoca en términos de posicionamiento político: es importante visibilizar a las y los muertos invisibles, politizar el malestar que generan sus muertes y permitir el derecho al duelo de sus familias, todo ello como parte de la reivindicación más general de un mundo sin fronteras. Dicho giro decolonial queda totalmente evidenciado mediante la propuesta de consulta ciudadana que Metromuster impulsó junto a otros colectivos, como parte del mismo proyecto. Fue un actor activo en la recogida de más de 15.000 firmas en favor de la celebración de un referéndum municipal para cambiar el nombre de la plaza Antonio López, de donde fue retirada la estatua del negrero esclavista, por el de plaza Idrissa Diallo, en homenaje no solamente a este muerto (o asesinado) en el CIE de Zona Franca, sino de manera más amplia a quienes perecieron en las fronteras o cruzando el Mediterráneo. La iniciativa no fue llevada a cabo debido al rechazo de la mayor parte de los partidos políticos que formaban entonces el pleno municipal.

\footnotetext{
34 Ver en este sentido el post de Harmonia CARMOnA, "El negro", Harmonia Carmona, entrada en el blog publicada el 20 de agosto de 2012 [en línea], http://harmoniacarmona.blogspot.com.es/2012/08/el-negro.html [Consulta: 20 de mayo de 2018]. Recoge algunas visiones maliciosas formuladas desde la prensa y el gobierno español al respecto del conflicto diplomático.

35 Judith Butler, Marcos de guerra. Las vidas lloradas, Barcelona, Paidós, 2010, pp. 50-51.
} 


\section{Conclusiones}

Los encierros, las redadas, las persecuciones a los vendedores ambulantes, la repatriación de los cadáveres, las luchas por el cierre del CIE, los rastros coloniales en la ciudad. Todas estas imágenes configuran una base para lo que aquí se han considerado como aportaciones de no ficción a las estéticas decoloniales. Esta idea, bien lejos de haber sido cerrada, esboza un programa de investigación todavía por desarrollar. Sin ir más lejos, cabría pensar, en el marco de dicha estética, la perspectiva de género, puesto que existen fronteras que afectan de manera particular a las mujeres migrantes, algo que aquí no se ha abordado debido al contenido de los títulos seleccionados.

Por otro lado, también resulta importante señalar un aspecto no previsto al inicio de la investigación, con el que la mayor parte de películas analizadas dialogan: la cuestión del turismo y de la imagen turística de la ciudad está presente de alguna manera en los relatos. En cierta manera, migrantes y turistas son dos figuras sociales, una en tránsito deseado y consumista, la otra en tránsito forzado debido a la situación de desigualdad en el país de origen y la calidad de la acogida, que indican maneras legales e ilegales de transitar por el mundo, así como la permeabilidad de la frontera cuando lo que se busca es ocio y disfrute temporal, que cabe contraponer a su violento hermetismo cuando de lo que se trata es de sobrevivir. En cualquier caso, la relación entre turismo y migraciones queda como un elemento más a explorar desde el punto de vista de la estética decolonial.

Quiero proponer, ya para acabar, dos ideas algo provocadoras. La primera es que el pensamiento decolonial funciona como marco teórico que puede combinarse, sin caer en el racismo epistémico ni restar su importancia, con otras perspectivas críticas afines políticamente, las cuales también buscan contribuir a la reparación de la herida colonial y a acabar con el sistema de fronteras y el racismo

Por último, en segundo lugar, una de las preguntas más extendidas y fecundas sobre la condición migrante contemporánea es aquella formulada por Spivak: ¿Pueden hablar los subalternos? Resulta importante afirmar con claridad y de manera provocativa, contrariamente a lo que piensa la filósofa india, que no solamente pueden hacerlo a través del suicidio y las autolesiones, sino que, a pesar de las dificultades y hostilidades manifiestas, existen en el campo del arte y las políticas de representación de no ficción algunos ejemplos de películas-voz que contribuyen a una finalidad ética y política evidente: la necesidad de des-colonizar la subjetividad, entendida como experiencia de frontera y como manera de mirar. Este escrito tiene lugar en un contexto local, Barcelona, donde cada vez se producen más formas de colaboración política en este sentido. Por ello, es una contribución humilde y apasionada, desde la reflexión estética, a la alianza de sensibilidades transformadoras que se está gestando.

JOAN MIQUEL GUAL es profesor de Historia del cine y artes en pantalla (asignatura sobre cine político de los años 60/70) en la Universitat Oberta de Catalunya (UOC). Licenciado en Comunicación Audiovisual (Universidad de Málaga), Máster en Teoría y práctica del documental creativo (Universitat Autònoma de Barcelona) y Doctor en Teoría, análisis y documentación cinematográficas (Universitat Pompeu Fabra). Entre sus principales intereses se encuentran la historia de las representaciones audiovisuales de Barcelona, por un lado, y el cine político de ficción y no ficción, por otro. Actualmente está investigando sobre diferentes iconografías relativas a la cuestión de la decolonialidad en la ciudad de Barcelona, prestando especial interés al cortometraje de no ficción.

Email: joan.m.gual@gmail.com

Código ORCID: https://orcid.org/0000-0001-6692-3287 